\title{
Method Development and Validation for
}

\section{Measuring $\mathrm{O}^{6}$-Methylguanine in Dried Blood Spot Using Ultra High-Performance Liquid Chromatography Tandem Mass Spectrometry}

This article was published in the following Dove Press journal:

Drug Design, Development and Therapy

\author{
Yahdiana Harahap (D) ${ }^{1,2}$ \\ Aurelia Maria Vianney' \\ Herman Suryadi ${ }^{\prime}$ \\ 'Faculty of Pharmacy, Universitas \\ Indonesia, Depok, West Java, 16424, \\ Indonesia; ${ }^{2}$ Indonesia Defense University, \\ Bogor, 16810, West Java, Indonesia
}

Correspondence: Yahdiana Harahap Email yahdiana@farmasi.ui.ac.id
Background: Cyclophosphamide is a nitrogen mustard chemotherapy drug that damages DNA through alkylation in the DNA base and produces DNA adducts. Alkylation that occurs in the N7 position of guanine base has a cytotoxic effect which is useful for cancer therapy. However, the alkylation that occurs in the $\mathrm{O} 6$ position of guanine bases can have mutagenic and carcinogenic effects that can trigger secondary cancer. This carcinogenic compound can be found in very low concentrations in cancer patients who had been receiving alkylating agents as their anticancer therapy. Analysis of $\mathrm{O}^{6}$-methylguanine can be one of the ways of therapeutic drug monitoring to avoid secondary cancer risk. This study aims to develop a sensitive, selective, and validated analytical method using Ultra-High-Performance Liquid Chromatography-Tandem Mass Spectrometry (UPLC-MS/MS).

Methods: Analysis of $\mathrm{O}^{6}$-methylguanine was done in Dried Blood Spot (DBS) and using allopurinol as an internal standard. The optimal analysis conditions were obtained using a C18 Acquity ${ }^{\circledR}$ Bridged Ethylene Hybrid (BEH) column $(1.7 \mu \mathrm{m}, 100 \mathrm{~mm} \times 2.1 \mathrm{~mm})$; mobile phase was $0.05 \%$ formic acid - acetonitrile $(95: 5 \mathrm{v} / \mathrm{v})$; flow rate $0.1 \mathrm{~mL} /$ minute; gradient elution for 6 minutes; and detection at m/z $165.95>149$ for $\mathrm{O}^{6}$-methylguanine and m/z $136.9>110$ for allopurinol.

Results: The present study has fulfilled the FDA validation parameter requirements. The method provides rapid, sensitive, and selective analysis of $\mathrm{O}^{6}$-methylguanine using UPLCMS/MS with a linear concentration range between $0.5-20 \mathrm{ng} / \mathrm{mL}$.

Keywords: cyclophosphamide, DNA adduct, $\mathrm{O}^{6}$-methylguanine, UPLC-MS/MS, dried blood spot

\section{Introduction}

Cyclophosphamide is a cytotoxic drug that is used for the treatment of many solid and hematologic neoplasms. ${ }^{1}$ It can be used for single or combination therapy for various indications such as malignant lymphoma, acute and chronic lymphatic leukemia, solid tumors such as breast cancer, or as immunosuppressants. Cyclophosphamide therapy can cause severe side effects such as anemia, leukocytopenia, and thrombocytopenia, gonadal toxicity, and can even cause secondary tumor development. ${ }^{2}$ It is also classified as a group 1 carcinogen compound (carcinogen in humans) by the IARC. ${ }^{3}$

Cyclophosphamide belongs to the group of nitrogen mustard which is a bifunctional alkylating agent that damages DNA and form DNA adduct. ${ }^{4}$ Alkylation of DNA bases gives rise to the mutagenicity and carcinogenicity of 
the cyclophosphamide, especially in the O6-guanine and N7-guanine positions. Alkylation in these positions causes crosslinks which indicate cytotoxic properties. ${ }^{5}$ The formation of DNA adducts is the initial step in the process of carcinogenic effects. Therefore, a method is needed to analyze DNA adduct from cyclophosphamide especially $\mathrm{O}^{6}$-methylguanine as a secondary cancer risk biomarker.

This study uses Dried Blood Spot samples for analysis. Dried Blood Spot is one of the biosampling techniques that was done using finger prick and the blood was collected to fill a premarked circle on a filter paper. ${ }^{6}$ Compared to previous studies that used venipuncture for blood sampling, ${ }^{7}$ DBS method is less invasive and only requires a small amount of blood thereby increasing patient comfort. ${ }^{8}$ In addition, the stability of the sample is better when using the DBS method compared to blood from veins. ${ }^{9}$

In this study, the development and validation of the analytical method were carried out using UPLC-MS/MS with allopurinol as the internal standard. This study aims to obtain the optimum and validated analytical method for measuring $\mathrm{O}^{6}$ methylguanine in Dried Blood Spot samples using Ultra-High -Performance Liquid Chromatography-Tandem Mass Spectrometry. Validation of this analytical method refers to the Food and Drug Administration, 2018. ${ }^{10}$ This research is expected to be useful for the implementation of drug therapy monitoring especially cyclophosphamide drug therapy.

\section{Materials and Methods}

\section{Chemical and Reagents}

$\mathrm{O}^{6}$-methylguanine, $\mathrm{N}^{7}$-methylguanine, adenine, and guanine were purchased from Sigma Aldrich (St. Louis, MO, USA). Internal Standard Allopurinol was obtained from Jiangsu Yew Pharm (Yixing, China). Reagents such as formic acid, acetic acid, methanol, ethanol, and acetonitrile were purchased from Merck Co. Ltd. (Darmstadt, Germany). Ultrapure water from Sartorius Water Filter System. Human blood was obtained from The Indonesian Red Cross (Jakarta, Indonesia). Perkin Elmer 226 paper from Perkin Elmer (Waltham, USA). The reagents for the DNA Isolation are Proteinase $\mathrm{K}$, Buffer AL, Buffer AW1, Buffer AW2, and Buffer AE (QIAamp DNA Mini Kits, QIAGEN).

\section{Preparation of Stock and Working Standard Solution}

A stock solution of $\mathrm{O}^{6}$-methylguanine and allopurinol was prepared at $1.0 \mathrm{mg} / \mathrm{mL}$ by diluting them in methanol. A series of working standard solutions at appropriate concentration levels were obtained via diluting each standard solution with water containing $0.5 \%(\mathrm{v} / \mathrm{v})$ formic acid. Calibration samples were prepared by diluting a working solution using whole blood to obtain a calibration range of $0.5-20 \mathrm{ng} / \mathrm{mL}$. Quality control samples were prepared at $1.5 \mathrm{ng} / \mathrm{mL}$ (QCL), $10 \mathrm{ng} / \mathrm{mL}$ (QCM), and $15 \mathrm{ng} / \mathrm{mL}(\mathrm{QCH})$ for $\mathrm{O}^{6}$-methylguanine by diluting working solution in whole blood.

\section{UPLC-MS/MS Conditions}

The research was performed on an ACQUITY ${ }^{\mathrm{TM}}$ UPLC system (Waters Corp., Milford, MA, USA) and a Xevo TQD Triple Quadrupole mass spectrometer (Waters Corp., Manchester, UK) equipped with positive electrospray ionization $\left(\mathrm{ESI}^{+}\right)$. All data were acquired in centroid mode by the MassLynx ${ }^{\mathrm{TM}} \mathrm{NT} 4.1$ software and analyzed by the QuanLynx $^{\mathrm{TM}}$ program (Waters Corp., Milford, MA, USA). The analyte was separated on the Acquity ${ }^{\circledR}$ UPLC BEH $\mathrm{C}_{18}$ column $(1.7 \mu \mathrm{m}, 100 \mathrm{~mm} \times 2.1 \mathrm{~mm}$, Waters Corp., Milford, MA, USA). The mobile phase was $0.05 \%$ formic acid solution and acetonitrile; flow rate $0.1 \mathrm{~mL} /$ min; autosampler temperature at $8^{\circ} \mathrm{C}$; and the injection volume was $10 \mu \mathrm{L}$. The gradient elution was used for 6 minutes and shown in Table 1.

The mass spectrometric detector parameters were optimized and set as follows: capillary voltage of $3.50 \mathrm{kV}$, nitrogen desolvation temperature as $349^{\circ} \mathrm{C}$ with a flow rate of $643 \mathrm{~L} / \mathrm{h}$, column temperature of $40^{\circ} \mathrm{C}$, and degasser pressure of $0.69 \mathrm{psi}$. The cone voltage was $32 \mathrm{~V}$ for $\mathrm{O}^{6}$ methylguanine, $38 \mathrm{~V}$ for $\mathrm{N}^{7}$-methylguanine, $40 \mathrm{~V}$ for adenine, $35 \mathrm{~V}$ for guanine, and $35 \mathrm{~V}$ for allopurinol as IS. The detector was performed in positive ion mode obtained by positive mode of electrospray ionization $\left(\mathrm{ESI}^{+}\right)$technique and quantification was acquired with multiple reaction monitoring (MRM) with ion transition at $165.95 \rightarrow 149$ and $165.95 \rightarrow 134$ for $\mathrm{O}^{6}$-methylguanine, $\mathrm{m} / \mathrm{z} 165.95 \rightarrow$ 149 and $165.95 \rightarrow 124$ for $\mathrm{N}^{7}$-methylguanine, m/z 135.9 $\rightarrow 118.95$ for adenine, $\mathrm{m} / \mathrm{z} 151.9 \rightarrow 134.95$ for guanine and $\mathrm{m} / \mathrm{z} 136.9 \rightarrow 110$ for allopurinol as IS.

Table I The First Gradient Elution Profile

\begin{tabular}{|l|c|c|}
\hline Min to- & Mobile Phase A (\%) & Mobile Phase B (\%) \\
\hline 0.00 & 95 & 5 \\
1.00 & 90 & 10 \\
2.00 & 90 & 10 \\
2.10 & 95 & 5 \\
6.00 & 95 & 5 \\
\hline
\end{tabular}




\section{Preparation of Sample in Dried Blood Spot}

Blood samples were obtained from The Indonesian Red Cross (Jakarta, Indonesia) and were reviewed and approved by the Research Ethics Committees of "Dharmais" Cancer Hospital, Jakarta 11420, Indonesia (No.023/KEPK/II/2020). Calibration and quality control samples were prepared by pipetting $50 \mu \mathrm{L}$ of whole blood containing $\mathrm{O}^{6}$-methylguanine onto the Perkin Elmer 226 paper and dried at room temperature for 2 h. DBS discs were cut and inserted into a microtube. The IS solution, allopurinol, is made to a concentration of $1 \mu \mathrm{g} /$ $\mathrm{mL}$ and $20 \mu \mathrm{L}$ was added. Then, the sample was extracted using the QIAamp DNA Mini Kit. DNA extraction procedures refer to the QIAamp DNA Mini and Blood Mini Handbook $^{11}$ as follows:

- Dried Blood Spot sample in a $1.5 \mathrm{~mL}$ microcentrifugation tube was added $180 \mu \mathrm{L}$ of the ATL buffer and incubated at $85^{\circ} \mathrm{C}$. Then, $20 \mu \mathrm{L}$ of proteinase $\mathrm{K}$ solution was added and incubated at $56^{\circ} \mathrm{C}$. After that, $200 \mu \mathrm{L}$ of the $\mathrm{AL}$ buffer was added to the sample and incubated at $70^{\circ} \mathrm{C}$.

- Samples were added with $200 \mu \mathrm{L}$ ethanol (96-100\%) and the mixture is carefully transferred into the QIAamp mini spin column. QIAamp mini spin column was used in this extraction consisted of a designed silica layer that can trap the DNA on it when centrifuged.

- Then, AW1 and AW2 buffer was added to separate protein from DNA, therefore it increased the purity of DNA.

- Finally, the DNA on the silica layer was eluted using AE buffer and incubated at room temperature. The results of DNA extraction can be stored at $-20^{\circ} \mathrm{C}$.

The DNA solution was mixed with the same amount of ultrapure water and $90 \%$ formic acid. Then, the solution is heated at $85^{\circ} \mathrm{C}$ for 60 minutes. After that, the solution is cooled to room temperature and ready to be injected into UPLC-MS/MS.

\section{Method Validation}

Validation of this analytical method was assessed including Lower Limit of Quantification (LLOQ), calibration curve, selectivity, accuracy and precision, recovery, carryover, dilution integrity, matrix effect, and stability according to the Food and Drug Administration (FDA) Bioanalytical Method Validation Guidance for Industry. ${ }^{10}$

\section{Lower Limit of Quantification}

LLOQ was determined using blank samples and the lowest concentration of analytes in samples that can still be analyzed quantitatively. The analyte response on LLOQ must be 5 times greater than the analyte response on the blank sample. The accuracy and precision of the analyte response should be less than $\pm 20 \%$.

\section{Calibration Curve}

The calibration curve was tested using standard solutions that are prepared on the same biological matrix as the study samples including blank samples, zero calibrator, and at least 6 other concentration points. The calibration curve acceptance criteria are that the analyte concentration is not more than $\pm 15 \%$ at all concentrations other than LLOQ and the analyte concentration is not more than \pm $20 \%$ at LLOQ concentration. At least $75 \%$ of the calibration standards with a minimum of 6 concentrations must meet these requirements.

\section{Selectivity}

The selectivity of the analytical method was evaluated using blank and LLOQ concentration. The requirement for selectivity is the peak response area of the analyte in the blank matrix obtained no more than $\pm 20 \%$ of the LLOQ peak area and no more than $5 \%$ in the internal standard.

\section{Accuracy and Precision}

Accuracy and precision were evaluated by assessing repeat analysis at four concentration levels in the measurement range, namely, LLOQ, QCL, QCM, and QCH over three consecutive days. The accuracy (\%diff) and precision (\% CV) should be within $\pm 20 \%$ for LLOQ and should be within $\pm 15 \%$ for QC samples.

\section{Recovery}

The recovery values were obtained at three QC levels (QCL, QCM, and QCH) by comparing the results of extracted samples with spiked post-extraction samples. Recovery values (\%) do not have to be $100 \%$, but the analytical, and standard recovery must be consistent and reproducible.

\section{Carryover}

Carryover was evaluated by injecting blank samples after samples with high concentrations or calibration standards at the upper limit of quantification (ULOQ). Carryover 
should not be greater than $20 \%$ of the analyte response at the lower limit of quantification (LLOQ) concentration and not greater than $5 \%$ for the internal standard.

\section{Dilution Integrity}

The dilution integrity was assessed by mixing the matrix with the analyte at the concentration above the ULOQ and diluting the sample with a blank matrix. The dilution integrity is stated to meet the requirements if the accuracy and precision are not more than $\pm 15 \%$.

\section{Matrix Effect}

Matrix effect was evaluated at QCL and QCH by comparing the results of spiked post-extraction samples and standard solutions containing analyte at equivalent concentrations. The coefficient of variation $(\% \mathrm{CV})$ of the matrix effect should not greater than $\pm 15 \%$. The standardized matrix factor values with the internal standard should obtain the acceptance range of 0.8 to $1.2{ }^{12}$

\section{Stability}

The stability tested includes stock solution stability, autosampler stability, short-term stability, and long-term stability. Stock solution stability of $\mathrm{O}^{6}$-methylguanine and allopurinol was evaluated in the short term at room temperature and long term at $-4^{\circ} \mathrm{C}$. The \%diff value of the stock solution stability test should not exceed $\pm 10 \% .{ }^{13}$ The other stability test was evaluated using QCL and QCH concentration. Autosampler stability was tested at autosampler temperature, short-term stability at room temperature, and long-term stability was tested at the freezer $-20^{\circ} \mathrm{C}$. The accuracy (\%diff) and $\% \mathrm{CV}$ at each level should not exceed $\pm 15 \%$.

\section{Results and Discussion}

Highly sensitive and selective analytical method is needed for the determination of DNA adduct because it is generally found in a very small level. Therefore, this study used UPLC-MS/MS as the instrument chosen. The UPLC-MS /MS is considered as the best choice for supporting bioanalytical studies due to high sensitivity, selectivity, and rapidity.

\section{Method Development Optimization of Mass Condition}

Mass spectrometric conditions were tuned in positive ionization mode related to analyte basic properties. The chemical structure is shown in Figure 1. The spectra showed a high-intensity signal at $\mathrm{m} / \mathrm{z} 165.95 \rightarrow 149$ and $165.95 \rightarrow$

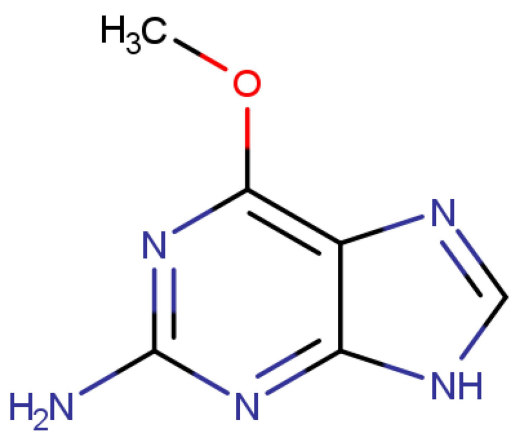

Figure $10^{6}$-methylguanine chemical structure.

134 for $\mathrm{O}^{6}$-methylguanine, $\mathrm{m} / \mathrm{z} \quad 165.95 \rightarrow 149$ and 165.95 $\rightarrow 124$ for $\mathrm{N}^{7}$-methylguanine, $\mathrm{m} / \mathrm{z} 135.9 \rightarrow 118.95$ for adenine, $\mathrm{m} / \mathrm{z} 151.9 \rightarrow 134.95$ for guanine and m/z 136.9 $\rightarrow 110$ for allopurinol as IS, respectively. The fragmentation spectrum of $\mathrm{O}^{6}$-methylguanine and $\mathrm{N}^{7}$ methylguanineare is shown in Figure 2. The capillary voltage used was $3.50 \mathrm{kV}$, nitrogen desolvation temperature was $349^{\circ} \mathrm{C}$ with a flow rate of $643 \mathrm{~L} / \mathrm{h}$, column temperature of $40^{\circ} \mathrm{C}$, and the degasser pressure of 0.69 psi. The cone voltage was $32 \mathrm{~V}, 38 \mathrm{~V}, 40 \mathrm{~V}, 35 \mathrm{~V}$ and 35 $\mathrm{V}$ for $\mathrm{O}^{6}$-methylguanine, $\mathrm{N}^{7}$-methylguanine, adenine, guanine, and allopurinol, respectively.

\section{Optimization of Mobile Phase Combination}

The selection of the mobile phase combination was carried out in 4 variations, namely, $0.05 \%$ acetic acid solution - acetonitrile, $0.05 \%$ acetic acid - methanol, $0.05 \%$ formic acid - acetonitrile, and $0.05 \%$ formic acid - methanol. In this study, a combination of $0.05 \%$ formic acid - acetonitrile was chosen because it produced a better chromatogram with the largest area.

\section{Optimization of Mobile Phase Composition}

The selection of the composition of the mobile phase is carried out using a combination of $0.05 \%$ acetic acid acetonitrile which is divided into 4 composition variations, namely 95:5, 90:10, 80:20, and 50:50. Based on the results, the composition of the mobile phase 95:5 produces the largest area. Therefore, composition 95: 5 was chosen for use in the analysis.

\section{Optimization of Flow Rate}

In this experiment, variations in the flow rate are $0.1 \mathrm{~mL} / \mathrm{min}, 0.2 \mathrm{~mL} / \mathrm{min}$ and $0.3 \mathrm{~mL} / \mathrm{min}$. Based on the results, increasing the flow rate has been shown to accelerate the retention time of the analyte. However, 
A O6-MEG MASS FRAGMENT
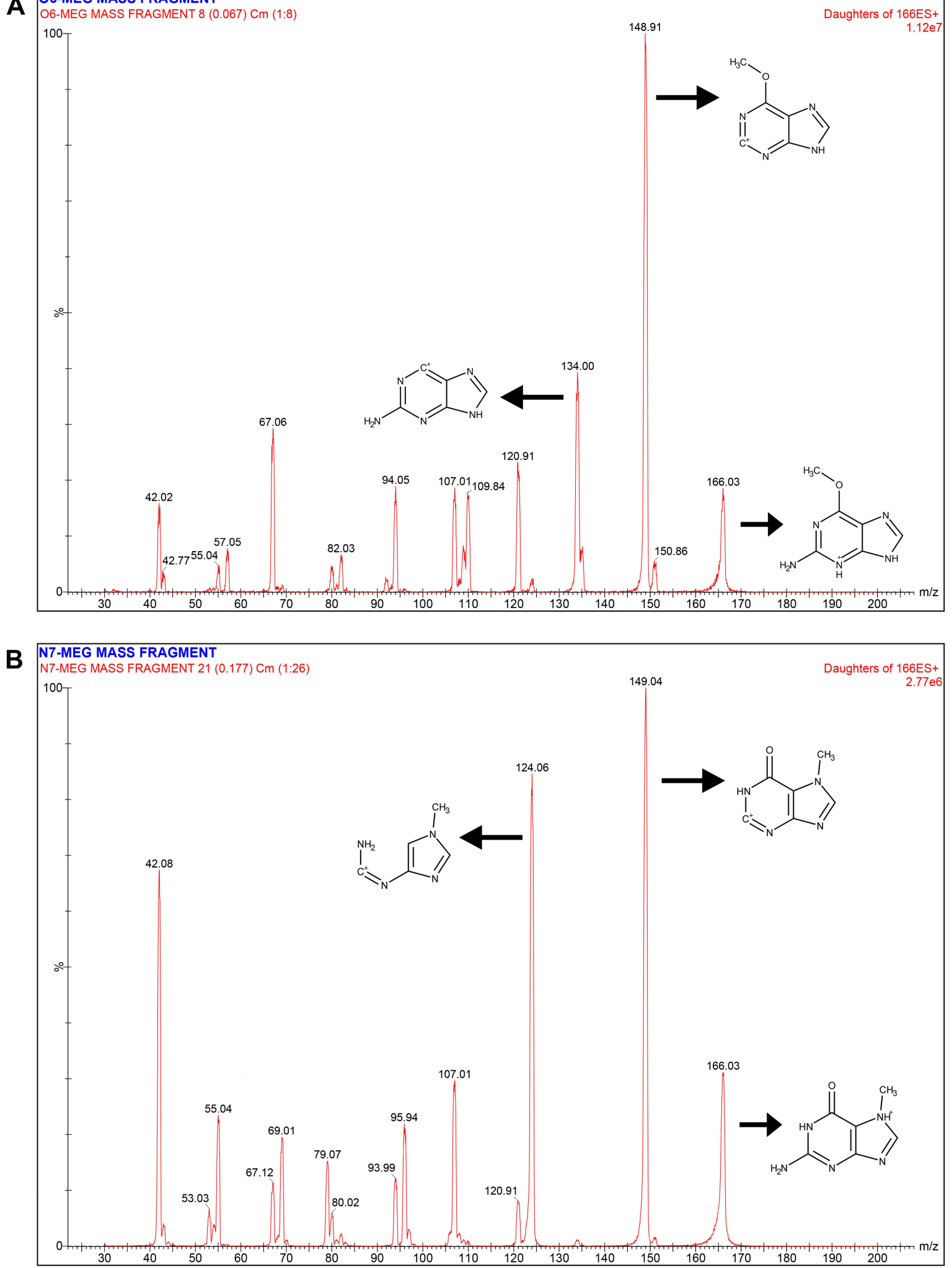

Figure 2 Fragmentation spectrum of $\left(\right.$ A) $\mathrm{O}^{6}$-methylguanine and (B) $\mathrm{N}^{7}$-methylguanine.

the faster flow rate can increase column pressure which causes the column to become damaged quickly. The use of a flow rate of $0.1 \mathrm{~mL} / \mathrm{min}$ gives the greatest peak area even with a longer retention time of $3.47 \mathrm{~min}$. Therefore, variations in the flow rate of $0.1 \mathrm{~mL} / \mathrm{min}$ were chosen for use in this study. 


\section{Optimization of Mobile Phase Gradient Elution}

Gradient elution was usually done to increase the elution strength which can produce a better peak shape and a larger peak area response. In this experiment, a gradient elution test was carried out using 2 variations as shown in Tables 1 and 2 . The use of a gradient elution produces a good chromatogram with a sharper peak shape compared to isocratic conditions. Therefore, the gradient elution profile 2 was chosen.

\section{System Suitability Test}

After obtaining the optimum analysis conditions, a system suitability test is then performed to ensure that the systems are working properly and are ready to be used for analysis. In this study, the peak area coefficient of variation $(\% \mathrm{CV})$ results were $0.68 \%$ for $\mathrm{O}^{6}$-methylguanine and $1.0 \%$ for allopurinol. The results also showed a $\% \mathrm{CV}$ value of $0.14 \%$ for the retention time of the two compounds. This shows that the system can be used to start the analysis and has fulfilled the requirements that $\% \mathrm{CV}$ value does not more than $6 \%$. ${ }^{14}$

\section{Optimization of Sample Preparation}

Optimization of DBS sample preparation is done by optimizing the drying time and spotting volume. In this study, optimization of the drying time of DBS samples was evaluated with time variations of $60 \mathrm{~min}, 120 \mathrm{~min}$, and $180 \mathrm{~min}$. From the experiments carried out, it is known that $120 \mathrm{~min}$ is sufficient time and provides the greatest response area of chromatogram. Therefore, $120 \mathrm{~min}$ is determined as the optimal drying time for DBS samples. After drying time is optimized, the spotting volume is optimized to get the optimal blood volume that must be spotted on DBS paper. Optimization is evaluated using three variations in the spotting volume of 30,40 , and $50 \mu \mathrm{L}$. Based on the results, the response of the peak area of the $50 \mu \mathrm{L}$ gives the greatest results. Therefore, a spotted volume of $50 \mu \mathrm{L}$ was chosen as the optimal spotted volume.

\section{Method Validation}

\section{Lower Limit of Quantification}

LLOQ determines the sensitivity of a method and needs to be determined during method development. LLOQ test for $\mathrm{O}^{6}$ -

Table 2 The Second Gradient Elution Profile

\begin{tabular}{|l|c|c|}
\hline Min to- & Mobile Phase A (\%) & Mobile Phase B (\%) \\
\hline 0.00 & 90 & 10 \\
1.00 & 95 & 5 \\
2.00 & 95 & 5 \\
2.10 & 90 & 10 \\
6.00 & 90 & 10 \\
\hline
\end{tabular}

methylguanine at a concentration of $0.5 \mathrm{ng} / \mathrm{mL}$ resulted in a value of $\%$ diff which ranged from $-8.90 \%$ to $11.40 \%$ with a $\% \mathrm{CV}$ of $8.95 \%$. This data is shown in Table 3. Based on these results, it is known that the accuracy and precision of the concentration of $0.5 \mathrm{ng} / \mathrm{mL}$ meet the LLOQ requirements on FDA, 2018. This LLOQ concentration was the same as previous studies that carried out $\mathrm{O}^{6}$-methylguanine analysis in blood samples. ${ }^{7}$ This shows that Dried Blood Spot samples can provide the same sensitivity as blood samples.

\section{Calibration Curve}

The calibration curve was made from a concentration of $0.5 \mathrm{ng} / \mathrm{mL}$ to $20 \mathrm{ng} / \mathrm{mL}$ with 6 concentration levels, blank, and zero samples. The calibration curve obtained was linear and meets the requirements of the correlation coefficient (r) value greater than $0.98 .^{15}$ The results of the calibration curve experiment showed that the \%diff obtained fulfilled the requirements. Data of $\mathrm{O}^{6}$-methylguanine inter-day calibration curves are shown in Table 4.

\section{Selectivity}

Selectivity is a test parameter evaluated to ensure that the method used can measure analytes accurately. Based on results, the selectivity test was fulfilled the FDA requirements with \%interference of the analyte between $8.64-13.54 \%$ and \%interference of allopurinol between $1.329-2.022 \%$. The chromatograms of blank, LLOQ, and QC samples are shown in Figure 3.

Table 3 The Accuracy and Precision from LLOQ of $O^{6}$ Methylguanine

\begin{tabular}{|l|c|c|c|}
\hline $\begin{array}{l}\text { LLOQ Conc. } \\
\text { (ng/mL) }\end{array}$ & $\begin{array}{c}\text { Measured Conc. } \\
\text { (ng/mL) }\end{array}$ & $\begin{array}{c}\text { Accuracy } \\
\text { (\%Diff) }\end{array}$ & $\begin{array}{c}\text { Precision } \\
\text { (\%CV) }\end{array}$ \\
\hline 0.50 & 0.46 & -8.24 & 8.95 \\
& 0.56 & 11.40 & \\
& 0.48 & -4.79 & \\
& 0.52 & 4.48 & \\
& 0.46 & -8.90 & \\
\hline
\end{tabular}

Table 4 Data of Inter-Day Calibration Curve of $\mathrm{O}^{6}$ Methylguanine

\begin{tabular}{|l|c|c|c|}
\hline Replica Inter-Day & Slope & Intercept & R \\
\hline I & 0.1006 & 0.0242 & 0.9961 \\
2 & 0.0907 & 0.0141 & 0.9993 \\
3 & 0.0902 & 0.0145 & 0.9978 \\
Mean & 0.9383 & 0.0176 & 0.9977 \\
\hline
\end{tabular}



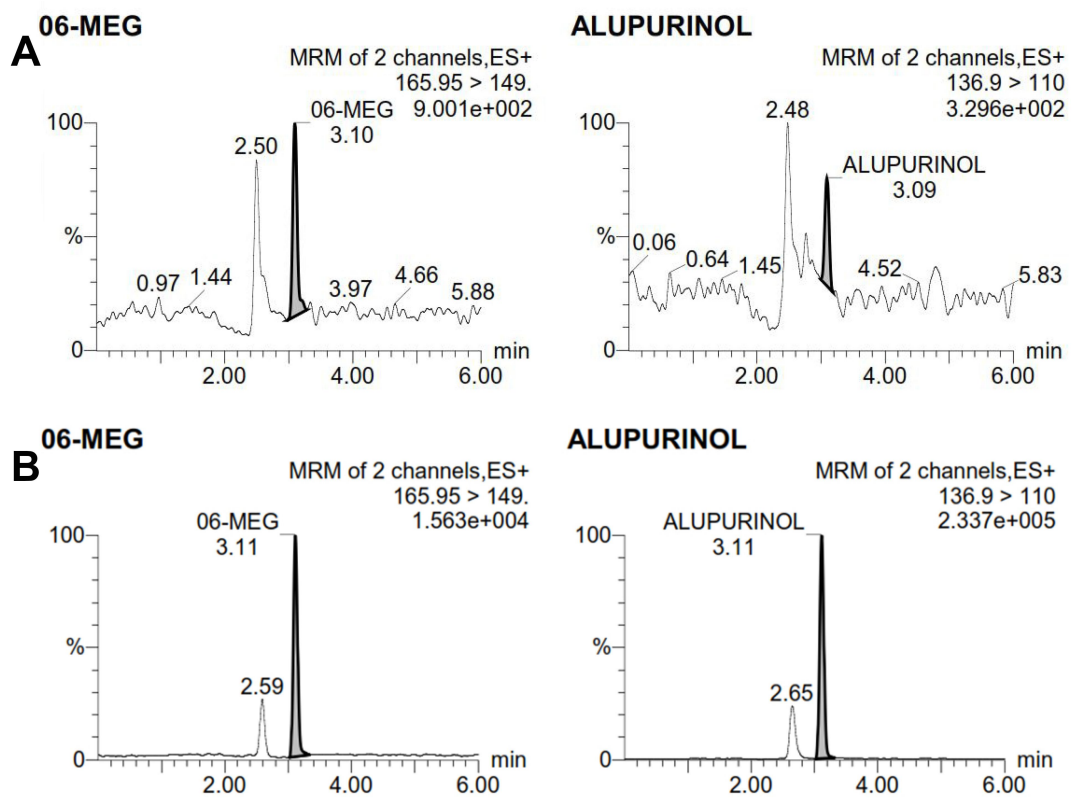

ALUPURINOL
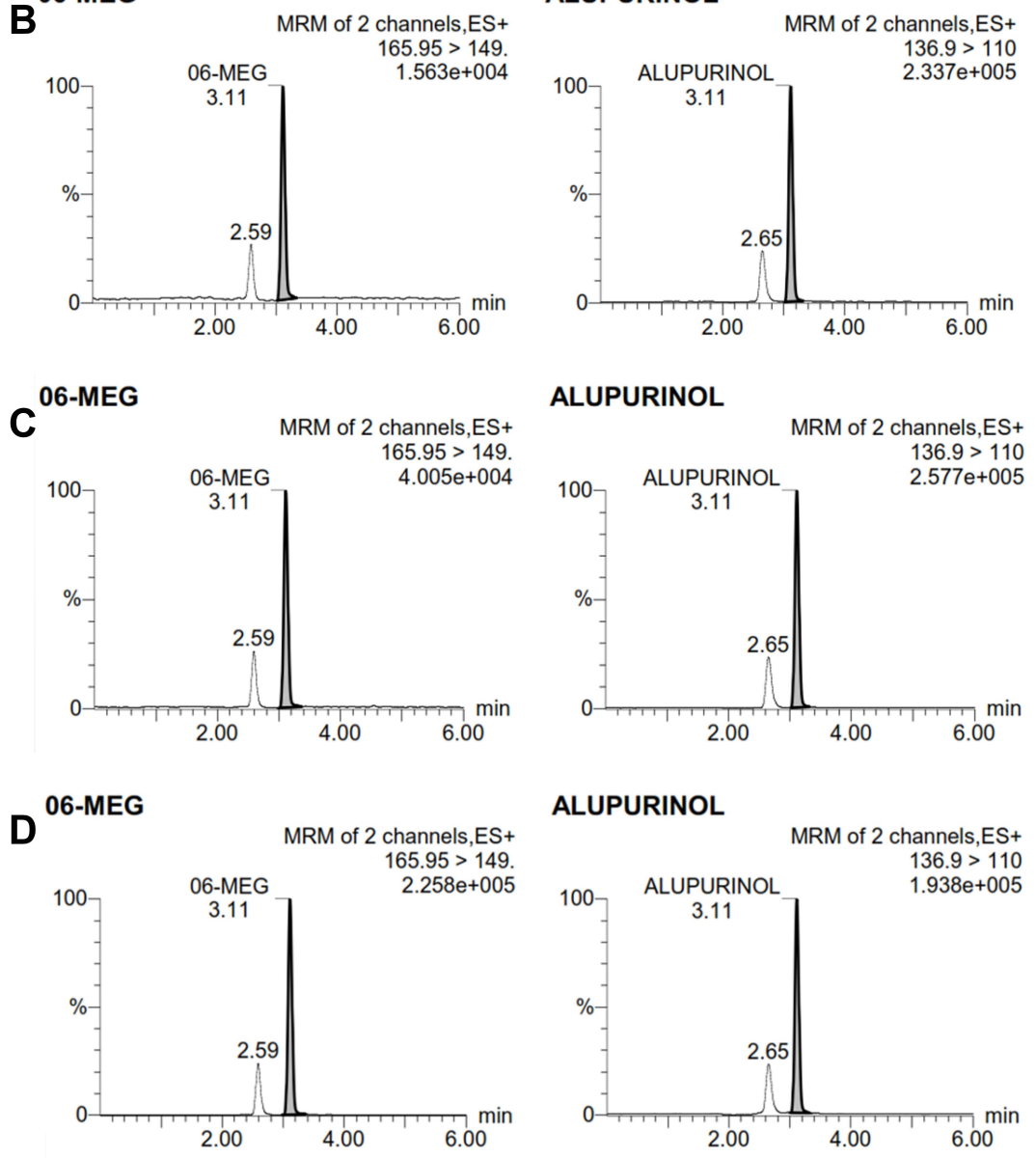

ALUPURINOL
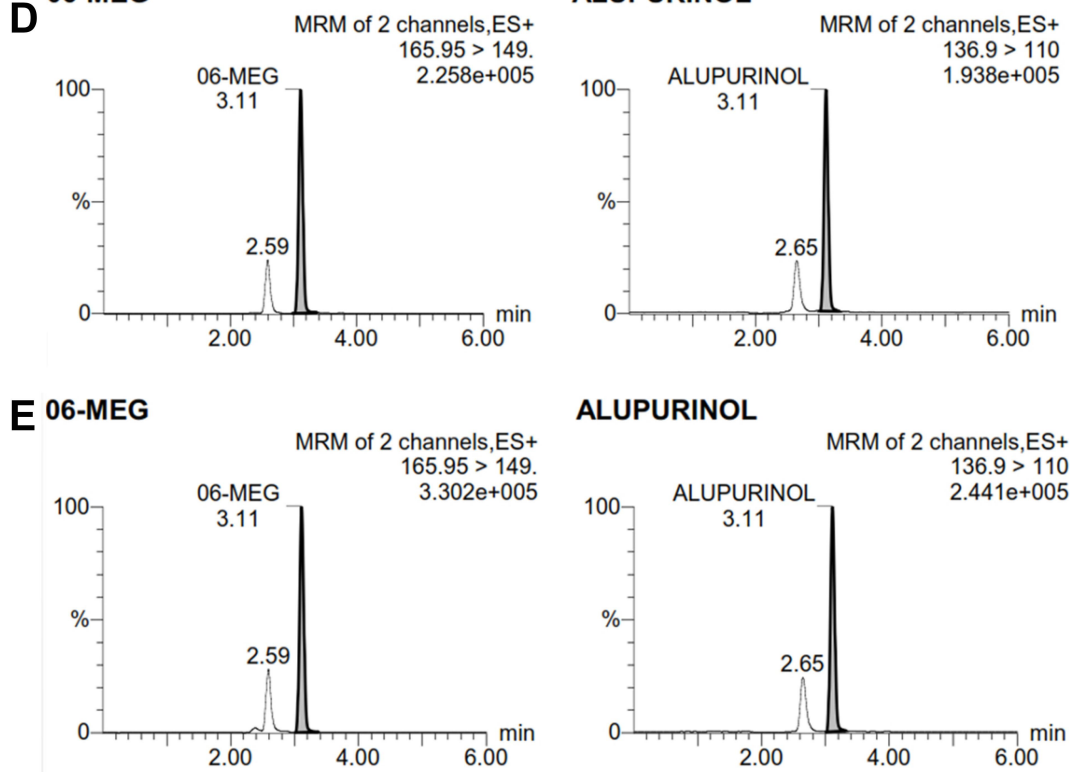

ALUPURINOL

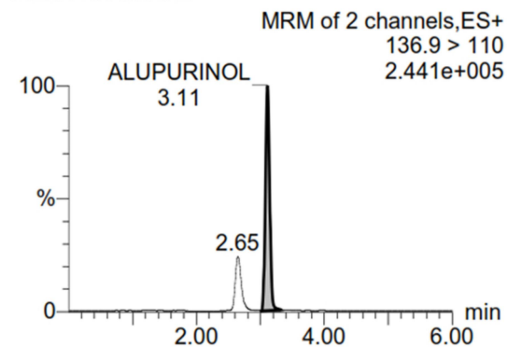

Figure 3 Representative UPLC-MS/MS chromatograms of $\mathrm{O}^{6}$-methylguanine and allopurinol in (A) blank DBS; (B) DBS with analyte at LLOQ; (C) QCL; (D) QCM; (E) $\mathrm{QCH}$. 


\section{Accuracy and Precision}

Accuracy and precision tests were carried out using 4-level concentrations, namely, LLOQ, QCL, QCM, and QCH. The intraday accuracy value of $\mathrm{O}^{6}$ methylguanine ranged from 91.99-106.29\% with \% $\mathrm{CV}$ values $\leq 4.61 \%$. The interday accuracy value ranged from $96.23-109.45 \%$ with $\% \mathrm{CV}$ values $\leq 4.97 \%$. Based on the results, the accuracy and precision of $\mathrm{O}^{6}$ methylguanine meet the requirements with the value of $\%$ diff and $\% \mathrm{CV}$ at LLOQ concentrations do not more than $20 \%$ and the value of $\%$ diff and $\% \mathrm{CV}$ at other concentrations than LLOQ do not more than $15 \%$. Compared with previous study, ${ }^{7}$ this study showed homogen data with lower \%CV value. The intra- and inter-day accuracy and precision are shown in Table 5.

\section{Recovery}

The recovery test is performed to see the extraction efficiency on the sample. According to FDA 2018, the value of recovery in analysis using a biological matrix does not have to be $100 \%$. However, it needs to be consistent and reproducible Based on the test, the average recovery value for $\mathrm{O}^{6}$-methylguanine is $82.62 \%$ at QCL concentration, $82.50 \%$ at QCM concentration, and $83.29 \%$ at $\mathrm{QCH}$ concentration. In addition, the test results also showed $\% \mathrm{CV}$ for the concentrations of QCL, QCM, and QCH of 3.97\%, $2.71 \%$, and $5.90 \%$, respectively. The average recovery value obtained for the standard in allopurinol is $81.10 \%$ with a $\% \mathrm{CV}$ of $2.09 \%$.

\section{Carryover}

Carryover is a parameter that is tested to determine the availability of analytes in blank samples after injecting high concentration analytes (ULOQ). Based on the results, the value of carryover was $11.12 \%$ to $12.65 \%$ for $\mathrm{O}^{6}$-methylguanine and $1.30 \%$ to $1.68 \%$ for the internal standard allopurinol. These results indicate that the carryover of $\mathrm{O}^{6}$-methylguanine and allopurinol meets the 2018 FDA requirements.

\section{Dilution Integrity}

Dilution integrity tests showed the value of \%diff is obtained between $-3.70 \%$ and $14.62 \%$ with a $\% \mathrm{CV}$ value of $2.82 \%$ for the $2 \mathrm{QCH}$ concentration, $6.39 \%$ for the $\mathrm{QCH}$ concentration, and $3.90 \%$ for the $1 / 2 \mathrm{QCH}$ concentration. The results indicate that it meets the dilution integrity requirements with the value of \%diff and $\% \mathrm{CV}$ do not exceed $\pm 15 \%$.

\section{Matrix Effect}

The average matrix factor obtained was $95.69 \%$ for QCL concentration and $97.30 \%$ for QCH concentration with $\mathrm{CV}$ values for QCL and QCH, namely, $1.96 \%$ and $1.11 \%$. The results of testing the matrix effect on the internal standard allopurinol give an average matrix factor value of $89.83 \%$ with $\% \mathrm{CV} 4.60 \%$. There is little ion suppression from the matrix against the internal standard. This is due to the competition between the matrix and the internal standard in the process of adding charge in the mobile phase. The results of standardized normalized matrix factors obtained were $1.07 \%$ for the concentration of QCL and $1.09 \%$ for the concentration of $\mathrm{QCH}$ with the values of $\mathrm{CV}$ for QCL and QCH, respectively, 4.20\% and $5.03 \%$.

\section{Stability}

Stock solutions of $\mathrm{O}^{6}$-methylguanine and allopurinol were stable for $24 \mathrm{~h}$ in room temperature and $30 \mathrm{~d}$ in the refrigerator $\left(-4^{\circ} \mathrm{C}\right)$. The stability test results of $\mathrm{O}^{6}$ methylguanine and allopurinol showed in Table 6. The data indicate that $\mathrm{O}^{6}$-methylguanine and allopurinol are stable enough during sample preparation and storage conditions.

Table 5 The Intra- and Inter-Day Accuracy and Precision of $0^{6}$-Methylguanine

\begin{tabular}{|l|c|c|c|c|}
\hline \multirow{2}{*}{ Conc. (ng/mL) } & \multicolumn{2}{|c|}{ Intra-Day } & \multicolumn{2}{c|}{ Inter-Day } \\
\cline { 2 - 5 } & Mean Accuracy (\%Diff) & Precision (\%CV) & Mean Accuracy (\%Diff) & Precision (\%CV) \\
\hline 0.5 & $-3.38 \%$ to $8.10 \%$ & 4.61 & $-3.38 \%$ to $15.01 \%$ & 4.97 \\
5 & $1.84 \%$ to $5.22 \%$ & 1.35 & $1.35 \%$ to $6.07 \%$ & 1.35 \\
10 & $5.66 \%$ to $7.27 \%$ & 0.60 & $5.66 \%$ to $13.65 \%$ & 2.54 \\
15 & $-11.53 \%$ to $-1.52 \%$ & 4.60 & $-11.00 \%$ to $-0.72 \%$. & 4.91 \\
\hline
\end{tabular}


Table 6 The Stability Test Results of $0^{6}$-Methylguanine

\begin{tabular}{|l|c|}
\hline Stability Experiments & Stable to- \\
\hline Short-term storage $\left(24 \mathrm{~h} .25^{\circ} \mathrm{C}\right)$ & $24 \mathrm{~h}$ \\
Long-term storage (freezer $\left.-20^{\circ} \mathrm{C}\right)$ & 7 days \\
Autosampler $(24 \mathrm{~h})$ & $24 \mathrm{~h}$ \\
\hline
\end{tabular}

\section{Conclusion}

In conclusion, the method for measuring $\mathrm{O}^{6}$ methylguanine in Dried Blood Spot was successfully developed and validated. Compared with the previously used method, ${ }^{7}$ this method has improved with a less invasive biosampling method and a smaller volume of blood samples. The method provides a rapid, sensitive, and selective analysis of $\mathrm{O}^{6}$-methylguanine using UPLC-MS/MS with a linear concentration range between $0.5-20 \mathrm{ng} / \mathrm{mL}$.

\section{Ethics}

This study was conducted in accordance with the Declaration of Helsinki.

\section{Acknowledgments}

The authors acknowledge the financial support received from the Directorate of Research and Community Services (DRPM) Universitas Indonesia, Depok, Indonesia with grant number NKB-1272/UN2.RST/HKP.05.00/2020, for the financial support of this research. This study was reviewed and approved by the Research Ethics Committees of "Dharmais" Cancer Hospital, Jakarta 11420, Indonesia (No.023/KEPK/II/2020).

\section{Disclosure}

The authors report no conflicts of interest. The authors alone are responsible for the content and writing of this article.

\section{References}

1. Reddy H, Duffy A, Holtzman NG, Emadi A. The role of $\beta$ elimination for the clinical activity of hypomethylating agents and cyclophosphamide analogues. Am J Cancer Ther Pharm. 2016;3:1-8.

2. Timm R, Kaiser R, Lotsch J, et al. Association of cyclophosphamide pharmacokinetics to polymorphic cytochrome P450 $2 \mathrm{C} 19$. Pharmacogenomics J. 2005;5(6):365-373. doi:10.1038/sj.tpj.65 00330

3. International Agency for Research on Cancer. IARC monograph 100A. Paris: International Agency for Research on Cancer; 2012.

4. Robert JFH, Bast $\mathrm{C}$ Jr, Groce CM, et al. Holland-Frei Cancer Medicine. 9th ed. Vol. 2016. Hoboken, New Jersey: JohnWiley \& Sons, Inc.; 2017.

5. Katzung BG, Trevor AJ. Basic \& Clinical Pharmacology, Thirteenth. San Fransisco: McGraw-Hill Education; 2015.

6. Wilhelm AJ, den Burger JCG, Swart EL. Therapeutic drug monitoring by dried blood spot: progress to date and future directions. Clin Pharmacokinet. 2014;53:961-973. doi:10.1007/s40262-014-0177-7

7. Harahap Y, Andalusia R, Crystalia Y, Nurfaradilla S. Analysis of O6-methylguanine in cancer patient blood during administration of cyclophosphamide using ultra high performance liquid chromatography-tandem mass spectrometry. J Adv Med Pharm Sci. 2015;2:20-28. doi:10.9734/jamps/2015/12953

8. Ostler MW, Porter JH, Buxton OM. Dried blood spot collection of health biomarkers to maximize participation in population studies. J Vis Exp. 2014;1-9. doi:10.3791/50973

9. Kim HM, Park J, Phuoc Long N, Kim D, Kwon SW. Simultaneous determination of cardiovascular drugs in dried blood spot by liquid chromatography-tandem mass spectrometry. J Food Drug Anal. 2019;27:906-914. doi:10.1016/j.jfda.2019.06.001

10. Food and Drug Administration. Bioanalytical method validation guidance. Food Drug Adm. 2018;1043:25.

11. QIAGEN. QIAamp DNA mini and blood mini handbook Qiagen; 2016:1-72. Available from: http://www.qiagen.com/knowledge-andsupport/resource-center/resource-download.aspx?id=67893a91-946f49b5-8033-394fa5d752ea\&lang=en. Accessed February 18, 2021.

12. Li W, Zhang J, Francis LST. Handbook of LC-MS Bioanalysis. Canada: John Wiley \& Sons, Inc.; 2013.

13. Van De Merbel N, Savoie N, Yadav M, et al. Stability: recommendation for best practices and harmonization from the global bioanalysis consortium harmonization team. AAPS J. 2014;16:392-399. doi:10.1208/s12248-014-9573-z

14. Briscoe CJ, Stiles MR, Hage DS. System suitability in bioanalytical LC/MS/MS. J Pharm Biomed Anal. 2007;44:484-491. doi:10.1016/j. jpba.2007.03.003

15. Ghatol S, Vithlani V, Gurule S, Khuroo A, Monif T, Partani P. Liquid chromatography tandem mass spectrometry method for the estimation of lamotrigine in human plasma: application to a pharmacokinetic study. J Pharm Anal. 2013;3:75-83. doi:10.1016/ j.jpha.2012.09.001

\section{Publish your work in this journal}

Drug Design, Development and Therapy is an international, peerreviewed open-access journal that spans the spectrum of drug design and development through to clinical applications. Clinical outcomes, patient safety, and programs for the development and effective, safe, and sustained use of medicines are a feature of the journal, which has also been accepted for indexing on PubMed Central. The manuscript management system is completely online and includes a very quick and fair peer-review system, which is all easy to use. Visit http://www. dovepress.com/testimonials.php to read real quotes from published authors. 